九州大学学術情報リポジトリ

Kyushu University Institutional Repository

\title{
Two-Dimensional Computation Model for Simultaneous Soil Water and Heat Transport in Bare Soil with Various Topography
}

Lamsal, Khadananda

Laboratory of Irrigation and Water Utilization Engineering, Faculty of Agriculture, Kyushu University

Kuroda, Masaharu

Laboratory of Irrigation and Water Utilization Engineering, Faculty of Agriculture, Kyushu University

Nakano, Yoshisuke

Laboratory of Irrigation and Water Utilization Engineering, Faculty of Agriculture, Kyushu University

https://doi.org/10.5109/24110

出版情報 : 九州大学大学院農学研究院紀要. 40 (1/2)，pp. 241-255，1995-12. Kyushu University バージョン：

権利関係 : 


\title{
Two-Dimensional Computation Model for Simultaneous Soil Water and Heat Transport in Bare Soil with Various Topography
}

\author{
Khadananda Lamsal, Masaharu Kuroda and Yoshisuke Nakano
}

\author{
Laboratory of Irrigation and Water Utilization Engineering \\ Faculty of Agriculture, Kyushu University, Fukuoka 812-81, Japan
}

(Received July 31, 1995)

\begin{abstract}
The amount of heat available on soil surface is one of the major factors, which affects the temperature and moisture content of soil profile. Previous researches reported that amount of accepted solar radiation differs with topographic features of field, which is ultimate source for heat available on soil surface. Moreover, temperature and moisture content of soil profile is affected by the inclination of field. Therefore, an investigation is carried out to varify the impact of topographic feature on simultaneous soil moisture and heat flow. Furthermore, the main factors which induce the heat and moisture flow in soils with inclined topography are also investigated. For this purpose research was conducted on flat field and on north and south facing field, with 20 " inclination.

The results showed that, south facing field has higher soil temperature profile and a bit drier soil moisture profile than in other types of topography. North facing field has lower soil temperature and slightly wetter soil moisture profile. In this study direction along the soil surface direction is expressed as surface direction and direction normal to surface direction is denoted as depth direction. Soil moisture flow along the surface direction can not be expected even topography has some inclination until and unless soil profile is too much wet to occur gravity flow or rainfall intensity is higher than intake rate of soil. It is further investigated that heat flow in soils is solely governed by the product of temperature gradient of depth direction and thermal conductivity. Whereas, soil moisture flow is significantly effected by the product of gravitational head gradient of depth direction and moisture conductivity i.e. the gradient of flux potential. In addition a considerable effects of the product of temperature gradient of depth direction and thermal diffusivity; and the product of moisture gradient of depth direction and moisture diffusivity is also found. Furthermore, it is investigated that no any types of gradient of surface direction has any effect on soil moisture and heat flow.
\end{abstract}

\section{INTRODUCTION}

Philip and de Vries (1957) had reported the influence of temperature gradient on moisture movement. Later de Vries (1958) had formulated simultaneous differential equations for the transport of moisture and of heat in porous media with considering influence of gravity and gradients of temperature and moisture. Since then a lot of research works have been carried out by various researchers on simultaneous moisture and heat flow. But, researches, with considering additional influence of inclination, are seems to be rare for investigating soil evaporation and simultaneous moisture and heat flow. Hanks and Ashcroft (1980) reported amount of heat available at the soil surface is one of the major factors for affecting soil temperature. Lamsal et al. (1995) has reported amount of accepted solar radiation differs with facing direction and inclination of the topography. Therefore, this research is designed to deal with the soil evaporation and simultaneous moisture and heat flow on flat as well as on inclined topography, with 
considering north and south face with $20^{\circ}$ slope. Moreover, this research is further designed to investigate which factors are mainly responsible to what extent for heat and moisture flow in soils and which are not. In this research impact of gravity, inclination of topography, gradients of temperature and moisture and accepted amount of solar radiation on considered topographic conditions are taken in to account.

\section{EXPERIMENTATION}

Experimental field was prepared as shown in Fig. 1. For experimentation half raised and half sunken $20^{\circ}$ inclined boxes, facing north and south direction, of $3.0 \mathrm{~m}$ length, $1.5 \mathrm{~m}$ width and $1.0 \mathrm{~m}$ depth were constructed and filled with sandy loam soil. In the same manner a flat sunken box of $1.5 \mathrm{~m}$ length, $1.5 \mathrm{~m}$ width and $1.0 \mathrm{~m}$ depth was also prepared and filled with the same soil. Then the soil was allowed to be compacted for 2 months with leaving idle. For experimentation tensiometers at 6 different $\operatorname{depths}(i . e .5,15,25$, 35,45 and $75 \mathrm{~cm}$ ) were installed on bottom, center and top locations of each facing field. Whereas, tensiometers were installed only on center of flat field at the same depths. And thermocouples were installed on the centre of all the fields at 5 different depths of
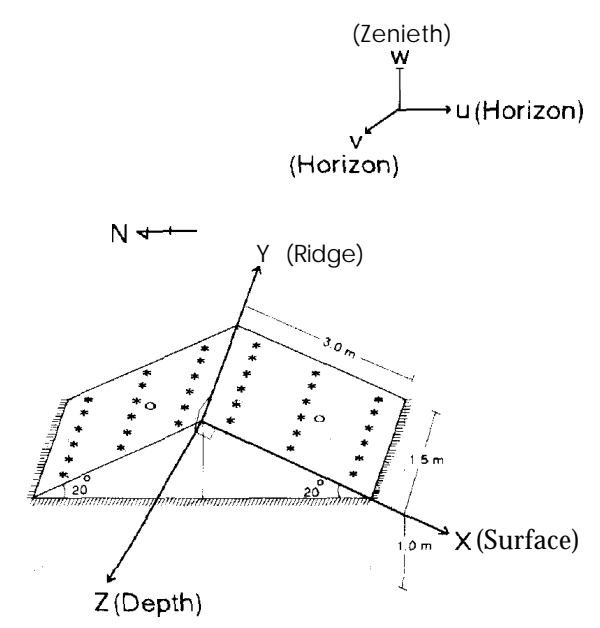

inclined field

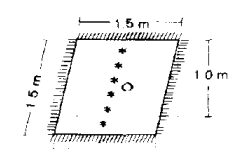

* - Locations of tensiometer

o-Locations of thermocouple

Flat field

Fig. 1. Layout of experimental field 
$0,2,5,15$ and $35 \mathrm{~cm}$ from soil surface for soil temperature measurement. The soil temperature was measured at an intervals of 30 minutes. The tensiometers reading were taken once a day at 6:00 a.m. morning. Solar radiation, air temperature, relative humidity and wind speed at $200 \mathrm{~cm}$ height were also measured an intervals of 1 minute.

\section{THEORITICAL CONSIDERATION}

\section{Derivation of solar radiation}

As already mentioned direct and diffused solar radiations were observed only for the flat case. Therefore, at first the component of direct solar radiation is derived by calculating the angle between the sun ray and normal vector of flat field. Then these values are converted for the cases of north facing and south facing field. It is performed with considering the angle between the normal vector of the field considered and the sun ray. For this $u$ direction is taken as north to south, $v$ direction is considered as east to west and $w$ direction from surface to zenieth. According to Tajima et al. (1977) relation to find angle between normal vector of field and sun ray is given as,

$$
\cos \phi=s_{1} \cdot n_{1}+s_{2} \cdot n_{3:}+s_{3} \cdot n_{: 3}
$$

where, $\phi=$ angle between normal vector of field and sun ray, $s_{1}, s_{2}$ and $s_{3:}=$ directional cosine of sun ray with respect to $\mathrm{u}, v$ and $w$ axis and $n_{1}, n_{2}$ and $n_{3}=$ directional cosine of normal vector of field on $\mathrm{u}, v$ and $w$ axis, respectively.

The directional cosine of flat field is considered as,

$$
n_{1}=0, n_{3}=0 \text { and } n_{3}=1
$$

Moreover,the directional cosine of north facing field is derived as,

$$
n_{1}=-\cos \left(\frac{\pi}{2}-\psi\right), n_{3}=0 \text { and } n_{3}=\cos \psi
$$

On the same way, the directional cosine of south facing field is dertermined as,

$$
n_{1}=\cos \left(\frac{\pi}{2}-\psi\right), n_{3}=0 \text { and } n_{3}=\cos \psi
$$

where, $\psi=$ angle of inclination of field (rad.).

Furthermore, the diffused solar radiation in the cases of north and south facing fields are derived from the observed values of flat field with considering the view factor of hemisphere as mentioned by Murai(1978).

As reported by van Bavel and Hillel (1976) the net radiation on the surface of bare soil is computated with given realtions.

$$
\begin{aligned}
& R_{u}=(1-\alpha) R_{s}+S K,-\varepsilon \cdot \sigma\left(T_{S}+273.16\right) \\
& S K, .=\sigma\left(T_{u}+273.16\right)^{\prime} \cdot(0.605+0.048 \sqrt{e})
\end{aligned}
$$


where, $R$, = net radiation $\left(\mathrm{cal} \cdot \mathrm{cm}^{-2} \cdot \mathrm{s}^{-1}\right), R_{S}=$ total incoming shortwave radiation $\left(\mathrm{cal} \cdot \mathrm{cm}^{-2} \cdot \mathrm{s}^{-1}\right)$, $S K_{L}=$ sky longwave radiation $\left(\mathrm{cal} \cdot \mathrm{cm}^{-2} \cdot \mathrm{s}^{-1}\right), \sigma=$ Boltzmann constant $\left(\mathrm{cal} \cdot \mathrm{cm}^{-2} \cdot \mathrm{s}^{-1} \cdot \mathrm{k}^{+}\right)$, $\varepsilon=$ surface emittance (0.95), $\mathrm{a}=$ albedo $(0.2), T,=$ air temperature $(" C), T_{\mathrm{s}}=$ soil surface temperature $\left({ }^{\circ} \mathrm{C}\right.$ ) and $e=$ actual vapour pressure $(\mathrm{mmHg})$.

\section{Moisture and heat flow}

The differential equations for simultaneous moisture and heat flow regarding experimental field conditions were derived as formulated by de Vries (1958), Hillel (1980) and Miyazaki et al. (1993). For formulation X direction (surface direction) is considered as soil surface direction from north to south, and $\mathrm{Z}$ direction (depth direction) is considered as direction normal to surface direction X. The non-linear two dimensional simultaneous moisture and heat flow equation for the experimental field conditions have the form of,

$$
\begin{gathered}
\left.\frac{\partial \theta}{\partial t}=\frac{\partial}{\partial x} \mid D_{t}(\theta) \frac{\partial T}{\partial x}\right]+\frac{\partial}{\partial z}\left[D_{t}(\theta) \frac{\partial T}{\partial z}\right]+\frac{\partial}{\partial x}\left[D_{\theta}(\theta) \frac{\partial \theta}{\partial x}\right]-\frac{\partial}{\partial x}\left[K(\theta) \frac{\partial(x \cdot \sin \alpha)}{\partial x}\right] \\
+\frac{\partial}{\partial z}\left[D_{\theta}(\theta) \frac{\partial \theta}{\partial z}\left|-\frac{\partial}{\partial z}\right| K(\theta) \frac{\partial(z \cdot \cos \alpha)}{\partial z} \mid\right. \\
\left.C_{U} \frac{\partial T}{\partial t}=\frac{\partial}{\partial x}\left[\lambda(\theta) \frac{\partial T}{\partial x}\right]+\frac{\partial}{\partial z} \mid \lambda(\theta) \frac{\partial T}{\partial z}\right]+L \cdot \rho_{\omega} \frac{\partial}{\partial x}\left[D_{\theta \nu}(\theta) \frac{\partial \theta}{\partial x}\right]+L \cdot \rho_{\omega} \frac{\partial}{\partial z}\left[D_{\theta \nu}(\theta) \frac{\partial \theta}{\partial z}\right]
\end{gathered}
$$

where, $L=$ latent heat of vaporization $\left(\mathrm{cal} \cdot \mathrm{g}^{-1}\right), \rho_{w}=$ density of water $\left(\mathrm{g} \cdot \mathrm{cm}^{-3}\right), \alpha$ $=$ angle of inclination of field ( $\mathrm{rad}.), z=$ soil depth $(\mathrm{cm}), \mathrm{x}=$ length in $\mathrm{X}$ direction $(\mathrm{cm})$, $\theta=$ volumetric water content $\left(\mathrm{cm}^{*} \cdot \mathrm{cm}^{* 3}\right), t=$ time $(\mathrm{s}), T=$ soil temperature $\left({ }^{\circ} \mathrm{C}\right), \mathrm{C}, .=$ volumetric heat capacity $\left(\mathrm{cal} \bullet \mathrm{cwP} *{ }^{\circ} \mathrm{C}^{-1}\right), \lambda=$ thermal conductivity $\left(\mathrm{cal} \cdot \mathrm{cm}^{-1} \cdot{ }^{\circ} \mathrm{C}^{1}\right.$. $\left.s^{-1}\right), k=$ hydraulic conductivity $\left(\mathrm{cm} \cdot \mathrm{s}^{-1}\right), D_{1}=$ soil thermal diffusivity $\left(\mathrm{cm}^{2} \cdot{ }^{\circ} \mathrm{C}^{-1} \cdot \mathrm{s}^{-1}\right), D_{\prime \prime}=$

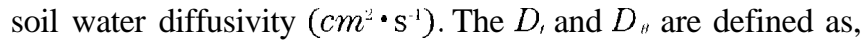

$$
\begin{aligned}
& D_{i}=D_{n}+D_{t u} \\
& D_{n}=D_{H}+D_{H}
\end{aligned}
$$

where, $D_{\|}=$liquid-phase thermal diffusivity, $D_{n}=$ vapour-phase thermal diffusivity, $D_{\theta \prime}=$ an isothermal liquid diffusivity and $D_{\theta \prime \prime}=$ an isothermal vapour diffusivity.

The above mentioned differential equations of simultaneous moisture and heat flow are solved by Line Successive Overrelaxation (LSOR) finite difference method as reported by Freeze (1971). The numerical solution for moisture flow by LSOR technique oriented in $\mathrm{Z}$ direction has taken the form of. 


$$
\begin{aligned}
& -\left|\frac{D_{\theta i, j-1}}{\Delta z_{j-1}\left(\Delta z_{j}+\Delta z_{j-1}\right)}\right| \theta_{i, j-1^{+}}^{\prime}\left|\frac{D_{\theta i, j}}{\Delta z_{j}\left(\Delta z_{j}+\Delta z_{j-1}\right)}+\frac{D_{\theta i, j-1}}{\Delta z_{j-1}\left(\Delta z_{j}+\Delta z_{j-1}\right)}+\frac{D_{\theta i, j}}{2 \Delta x^{2}}+\frac{D_{\theta i-1, j}}{2 \Delta x^{2}}+\frac{1}{\Delta t}\right| \\
& \theta_{i, j}^{t}-\left|\frac{D_{\theta i, j}}{\Delta z_{j}\left(\Delta z_{j}+\Delta z_{j-1}\right)}\right| \theta_{i, j+1}^{t}=\frac{\theta_{i, j}^{t-1}}{\Delta t}+\frac{D_{t i, j}}{\Delta x^{2}}\left(T_{i+1, j}^{t-1}-T_{i, j}^{t-1}\right)-\frac{D_{t i-1, j}}{\Delta x^{2}} \\
& \left(T_{i, j}^{t-1}-T_{i-1, j}^{i-1}\right)+\frac{D_{\theta i, j}}{2 \Delta x^{2}}\left(\theta_{i+1, j}^{t-1}-\theta_{i, j}^{t-1}+\theta_{i+1, j}^{t}\right)-\frac{D_{\theta i-1, j}}{2 \Delta x^{2}}\left(\theta_{i, j}^{t-1}-\theta_{i-1, j}^{t-1}-\theta_{i-1, j}^{t}\right)-\frac{1}{\Delta x} \\
& \left(K_{i, j} \cdot \sin \alpha-K_{i-1, j} \cdot \sin \alpha\right)+2 \frac{D_{t i, j}}{\Delta z_{j}\left(\Delta z_{j}+\Lambda z_{j-1}\right)}\left(T_{i, j+1}^{t-1}-T_{i, j}^{t-1}\right)-2 \frac{D_{t i, j-1}}{\Delta z_{j-1}\left(\Delta z_{j}+\Delta z_{j-1}\right)} \\
& \left(T_{i, j}^{t-1}-T_{i, j-1}^{t-1}\right)+\frac{D_{\theta i, j-1}}{\Delta z_{j}\left(\Delta z_{j}+\Delta z_{j-1}\right)}\left(\theta_{i, j+1}^{t-1}-\theta_{i, j}^{t-1}\right)-\frac{2}{\Delta z_{j-1}\left(\Delta z_{j}+\Delta z_{j-1}\right)}\left(\theta_{i, j}^{t-1}-\theta_{i, j-1}^{t-1}\right) \\
& -\frac{2}{\Delta z_{j}+\Delta z_{j-1}-\left(K_{i, j}, \cos \alpha-K_{i, j-1} \cdot \cos \alpha\right)}
\end{aligned}
$$

where, $\mathrm{i}=$ nodal points oriented in $\mathrm{X}$ direction and $j=$ nodal points oriented in $\mathrm{Z}$ direction, $\mathrm{AZ}=$ thickness of soil layer $(\mathrm{cm}), \mathrm{Ax}=$ distance between two adjacent nodal points in $\mathrm{X}$ direction $(\mathrm{cm})$.

The above presented numerical solution for moisture flow in $\mathrm{Z}$ direction has taken a tridiagonal matrix form as,

$$
-A_{j} \theta_{i, j-1}+B_{i} \theta_{i,-}^{\prime}-C_{j} \theta_{i,+1}^{\prime}=D_{1}
$$

Again, the numerical solution of heat flow oriented in $\mathrm{Z}$ direction by LSOR finite difference method has derived as under mention.

$$
\begin{aligned}
& -\left|\frac{\lambda_{i, j-1}}{\Delta z_{j-1}\left(\Delta z_{j}+\Delta z_{j-1}\right)}\right| T_{i, j-1}^{t}+\mid \frac{\lambda_{i, j}}{\Delta z_{j}\left(\Delta z_{j}+\Delta z_{j-1}\right)}+\frac{\lambda_{i, j-1}}{\Delta z_{j-1}\left(\Delta z_{j}+\Delta z_{j-1}\right)}+\frac{\lambda_{i, j}}{2 \Delta x^{2}} \\
& \left.+\frac{\lambda_{i-1, j}}{2 \Delta x^{2}}+\frac{C_{v}}{\Delta t}\left|T_{i, j}^{t}-\right| \frac{\lambda_{i, j}}{\Delta z_{j}\left(\Delta z_{j}+\Delta z_{j-1}\right)}\right] T_{i j+1}^{t}=\frac{C_{i} T_{i, j}^{t-1}}{\Delta t}+\frac{\lambda_{i, j}}{2 \Delta x^{2}}\left(T_{i+1, j}^{t-1}\right. \\
& \left.-T_{i, j}^{t-1}+T_{i+1, j}^{t}\right)-\frac{\lambda_{i-1, j}}{2 \Delta x^{2}}\left(T_{i, j}^{t-1}-T_{i-1, j}^{t-1}-T_{i-1, j}^{t}\right)+L \rho_{\omega}\left[\frac{D_{\theta v i, j}}{\Delta x^{2}}\left(\theta_{i+1, j}^{t}-\theta_{i, j}^{t}\right)\right. \\
& -\frac{D_{\theta i,-1, j}}{\Delta x^{2}}\left(\theta_{i, j}^{t}-\theta_{i-1, j}^{t}\right) \mid+\frac{\lambda_{i, j}}{\Delta z_{j}\left(\Delta z_{j}+\Delta z_{j-1}\right)}\left(T_{i, j+1}^{t-1}-T_{i, j}^{t-1}\right)-\frac{\lambda_{i, j-1}}{\Delta z_{j-1}\left(\Delta z_{j}+\Delta z_{j-1}\right)}
\end{aligned}
$$




$$
\begin{aligned}
& \left(T_{i, j}^{t-1}-T_{i, j-1}^{t-1}\right)+2 L \rho_{\omega} \mid \frac{D_{\theta v i, j}}{\Delta z_{j}\left(\Delta z_{j}+\Delta z_{j-1}\right)}\left(\theta_{i, j+1}^{t}-\theta_{i, j}^{l}\right) \\
& -\frac{D_{\theta v i, j-1}}{\Delta z_{j-1}\left(\Delta z_{j}+\Delta z_{j-1}\right)}\left(\theta_{i, j}^{t}-\theta_{i, j-1}^{t}\right) \mid
\end{aligned}
$$

On the same manner, the numerical solution for heat flow oriented in $\mathrm{Z}$ direction has the tridiagonal matrix form of,

$$
-A_{j}^{\prime} T_{i, 1}^{\prime}+B_{i}^{\prime} T_{i, j}^{\prime}-C_{j}^{\prime} T_{i+1}^{\prime}=D_{i}^{\prime}
$$

These formulated tridiagonal matrices of moisture and heat flow are solved by Gauss elimination method simultaneously with considering the given sets of boundary conditions as mentioned by Remson et al. (1971).

\section{Boundary conditions}

The moisture and temperature profile of soil is governed by available energy at the soil surface. The net radiation at soil surface is utilized in sensible, latent and soil heat fluxes. Therefore, energy balance at soil surface is considered as,

$$
R,=S+H+L E \quad \text { if } \quad z=0, x \geq 0, t \geq 0
$$

where, $R_{u}=$ net radiation $\left(\mathrm{cal} \cdot \mathrm{cm}^{2} \cdot \mathrm{s}^{-1}\right), \mathbf{S}=$ soil heat flux $\left(\mathbf{c a l} \cdot \mathrm{cm}^{\cdot} \cdot \mathrm{s}^{-1}\right), H=$ sensible heat flux $\left(\mathrm{cal} \cdot \mathbf{c m} " \cdot \mathrm{s}^{-1}\right)$ and $L E=$ evaporative heat flux $\left(\mathrm{cal} \cdot \mathrm{cm}^{-2} \cdot \mathrm{s}^{1}\right)$

As reported by Kjelgaard et al. (1994) sensible heat flux(H) can be calculated as given.

$$
H=P a C,\left[\begin{array}{cc}
\frac{T_{s}}{T_{s}} T_{L_{x}} \\
r_{\tilde{a}}
\end{array}\right]
$$

where, $\rho_{\mathrm{u}}=$ density of air $\left(0.0012 \mathrm{~g} \cdot \mathrm{cm}^{*}\right), \mathrm{C}_{,},=$specific heat of air at constant

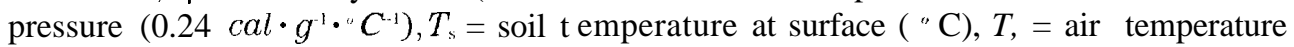
at specific height ( $C$ ) and $r_{\text {" }}=$ aerodynamic resistance of atmospheric boundary layer $\left(s . \mathrm{cm}^{-1}\right)$.

The relation mentioned by Goudriaan (1977) is used for computing evaporative heat flux (LE). The relation is given as,

$$
L E=\frac{\rho_{\alpha} C_{p}}{\gamma}\left[\frac{e_{s}-e_{\alpha}}{r_{\alpha}}\right]
$$

where, $\gamma=$ psychrometric constant $\left(0.66 \mathrm{mb} \cdot{ }^{*} \mathrm{C}^{-1}\right)$, e, $=$ vapour pressure at soil surface $(\mathrm{mb})$ and e, = vapour pressure at some specified height above soil surface (mb). 
The relation reported by Chamberlain (1968), Nakano et al. (1983) is used to find the atmospheric transfer resistance $\left(r_{1}\right)$. The relation is presented as,

$$
r_{a}=\frac{1}{k u_{*}} \ln \left[\frac{z}{z_{0}}\right]+\frac{1}{u_{*}} \cdot 0.52\left|\frac{u_{*} h}{v}\right|^{0.15}\left[\left.\frac{v}{D_{a}}\right|^{0.8}\right.
$$

where, $k=$ von karman constant $(0.4), u_{*}=$ friction velocity of air $\left(\mathrm{cm} \cdot s^{\prime}\right), z=$ height of measurement $(200 \mathrm{~cm}), z_{u}=$ roughness length $(0.02 \mathrm{~cm}), h=$ effective soil surface roughness $\left(=30 z_{i}\right), \nu=$ kinematic viscosity of air $\left(0.155 \mathrm{~cm}^{2} \cdot \mathrm{s}^{1}\right)$ and $D_{n}=$ molecular diffusivity of air $\left(0.249 \mathrm{~cm}^{-} \cdot \mathrm{s}^{-1}\right)$

The friction velocity of air is determined by a log-linear wind velocity profile relation above the soil surface.

$$
\begin{gathered}
u(z) k \\
u_{*}=\ln \left(z / z_{n}\right)
\end{gathered}
$$

where, $\mathrm{u}(z)=$ wind speed as a function of height $\left(\mathrm{cm} \cdot \mathrm{s}^{1}\right)$. In this research neutral adiabatic condition is assumed. No advection effects are expected. Therefore, wind speed value of $200 \mathrm{~cm}$ height is only used in the simulation process.

With referenced to Fritton et al. (1970) relations for removal of heat and moisture from the soil surface are derived as,

$$
\begin{aligned}
& S=-\lambda(\theta) \frac{d T}{d z}-L \rho_{\omega} D_{\theta}(\theta) \frac{d \theta}{d z} \quad \text { if } \quad z=0, x \geq 0, t \geq 0 \\
& \frac{E}{\bar{\rho}_{\omega}}=-D_{t}(\theta) \frac{d T}{d z}-D_{\theta}(\theta) \frac{d \theta}{d z}+K \cdot \cos \alpha \quad \text { if } \quad z=0, x \geq 0, t \geq 0
\end{aligned}
$$

where, $E=$ evaporation rate $\left(g \cdot \mathrm{cm}^{2} \cdot \mathrm{s}^{1}\right)$.

In addition, side and lower boundary conditions are set as under mention.

$$
\begin{array}{ll}
\frac{d T}{d x}=0, \frac{d \theta}{d x}=0, & \text { if } z \geq 0, x=0, \text { o r } x=M, t \geq 0 \\
\frac{d T}{d z}=0, \frac{d \theta}{d z}=0, & \text { if } z=N, x \geq 0, t \geq 0
\end{array}
$$

where, A4 = total length of the field considered and $\mathrm{N}=$ total depth considered.

\section{Initial condition}

The initial conditions set for the analysis are as follows.

$$
\theta_{i}=\theta_{o i}, T_{i}=T_{o i} \quad \text { if } \quad z \geq 0, x \geq 0, t=0
$$

where, $\theta_{0}=$ observed volumetric moisture content $\left(\mathrm{cm}^{3} \cdot \mathrm{cm}^{-}\right)$and $T,,,=$ observed soil temperature $\left({ }^{\prime} C\right)$ at each depth. 


\section{MODEL OPERATION}

As already mentioned the dimensions of inclined field and that of flat field are different. Therefore, the number of nodal points are to be considered for finite difference analysis are different for inclined and flat fields. In both the cases surface (X direction) was sectioned by grids of $10 \mathrm{~cm}$ and the depth of soil block ( $\mathrm{Z}$ direction) was sectioned by unequal thickness of grids. The depth of $0-100 \mathrm{~cm}$ was sectioned at $0,1,3,6,10,15,21,28,36$, $45,55,65,75,85$ and $100 \mathrm{~cm}$ depth as shown in Fig.2 Therefore, total nodal points incase of inclined fields are $465(31 \times 15)$ and $240(16 \times 15)$ in flat field. The average values of conductivities and diffusivities were calculated by using the values of two adjacent nodal points. Simulation was carried out with taking 1 minute time step. The initial soil temperature and moisture content in the soil profile were based on the observed values at 6:00 a.m. of March 31, 1995.

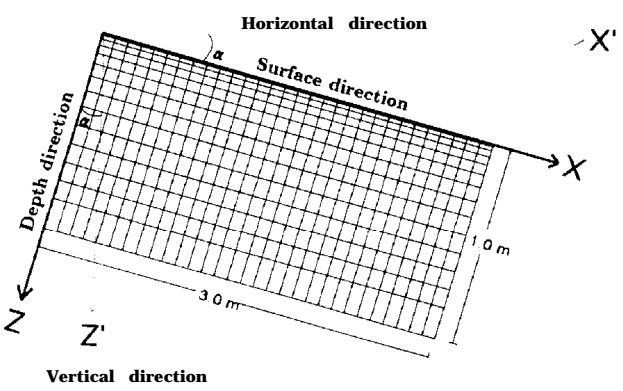

Fig. 2. Schematic diagram for finite difference analysis

At the side and lower boundary of experimental field the gradients of temperature and moisture is considered zero. The lower boundary was set at $100 \mathrm{~cm}$ depth. Therefore, it is neccessary to check whether the depth for lower boundary is enough or not. Because at the lower boundary amplitude of soil temperature is considered zero. As mentioned by Campbell (1985) the damping depth for soil temperature can be calculated as,

$$
z_{d}=\left[\frac{2 \lambda}{\omega C_{v}}\right]^{\frac{1}{2}}
$$

where, $z_{t}=$ damping depth $(\mathrm{cm}), \lambda=$ thermal conductivity $\left(3.1 \times 10^{33} \mathrm{cal} \cdot \mathrm{cm}^{-} \cdot{ }^{\circ} \mathrm{C} \cdot\right.$ $\left.s^{1}\right), \omega=2 \pi / 86400=$ angular frequency of oscillation $\left(7.27 \times 10^{-5} s^{-1}\right)$ and $\mathrm{C}, .=$ volumetric heat capacity $\left(0.7 \mathrm{cal} \cdot \mathrm{cm}^{-3} \cdot{ }^{\circ} \mathrm{C}^{-1}\right)$.

From the above relation damping depth $\left(z_{l}\right)$ for the soil profile of experimental field becomes $1 \mathrm{lcm}$. Hillel (1980) also reported the diurnal damping depth of $12 \mathrm{~cm}$. Moreover, Campbell (1985) has reported that at $z=z_{n}$, the amplitude is $e^{-1}=0.37$ times its value at the surface. The temperature at 2-3 damping depths would therefore be expected to be about the mean temperature for the period of oscillation because temperature fluctuations would be only 5-10 percent of the temperature fluctuation at the surface. The above mentioned facts suggests that setting of lower boundary at $100 \mathrm{~cm}$ depth is enough and reasonable. 


\section{RESULTS AND DISCUSSION}

\section{Soil temperature}

A differences in soil temperature profile is found among the experimental fields. Soil temperature of south facing field is slightly higher than that of flat field. Surface soil temperature reached maximum of about $38{ }^{\circ} \mathrm{C}$ in noon time and minimum of about $3{ }^{\circ} \mathrm{C}$ in morning i.e. around 6:00 a.m. in case of south facing field. The minimum temperature of surface are almost the same in all the cases of south, north and flat fields. But maximum soil surface temperature reached about $36.5^{\circ} \mathrm{C}$ and $34.0^{\prime \prime} \mathrm{C}$ in case of flat and

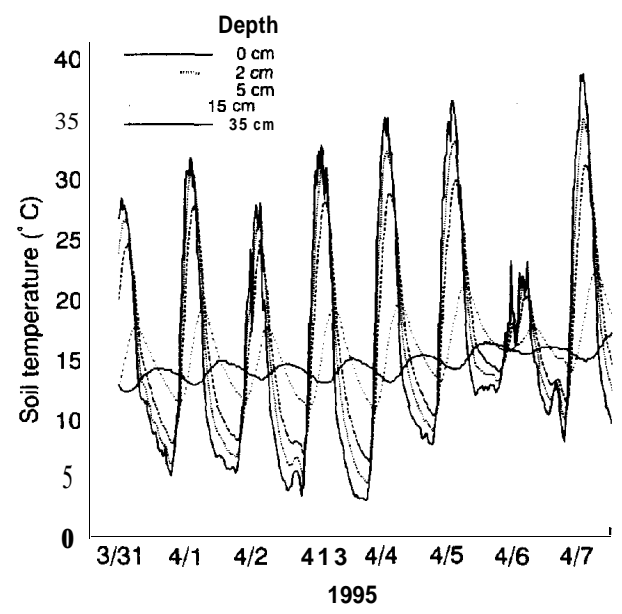

Fig. 3a. Observed soil temperature on south facing field.

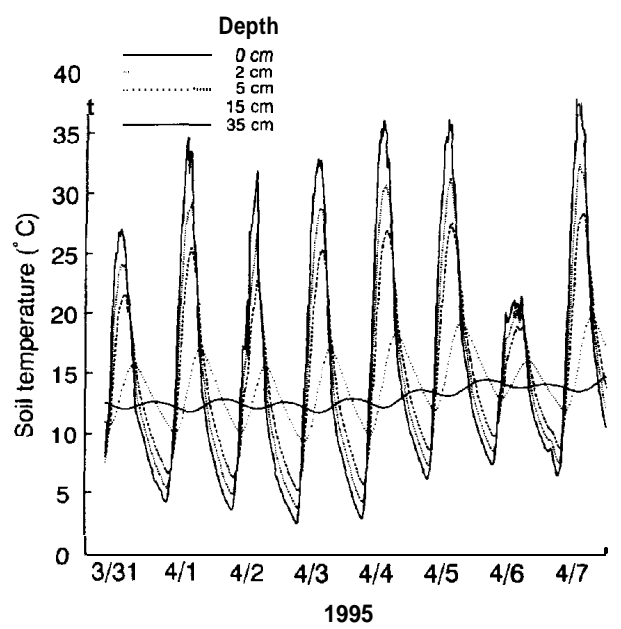

Fig. 4a. Simulated soil temperature on south facing field.

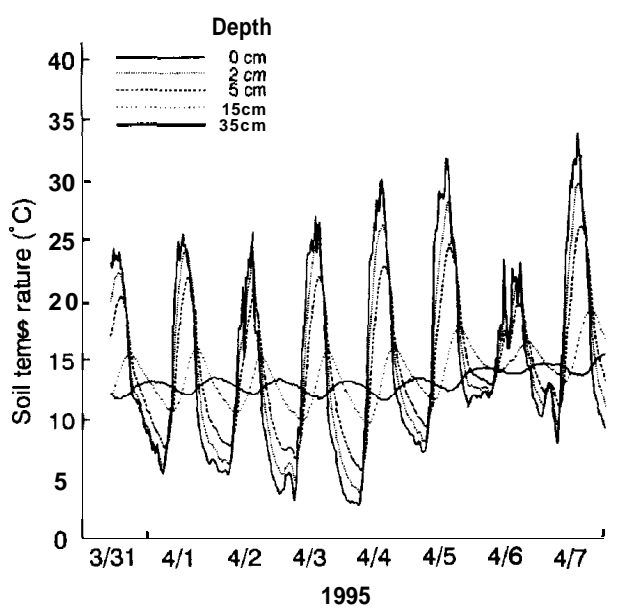

Fig. 3b. Observed soil temperature on north facing field.

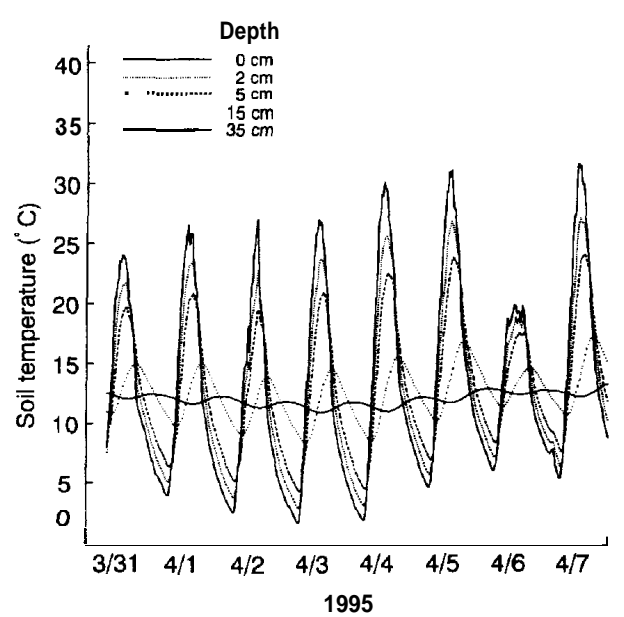

Fig. 4b. Simulated soil temperature on north facing field. 
north facing field, respectively. It is considered mainly due to the different amount of accepted solar radiation on different field conditions. For example, observed soil temperature profile of south and north facing fields are presented in Fig.3a and Fig.3b, respectively. Similarly, simulated soil temperature profile of south and north facing fields are shown in Fig.4a and Fig.4b, respectively for comparision.

The simulated results of both cases are well concoide with their respective observed values. It indicates that simulation model is very reliable. Moreover, time lag is clearly presented for reaching the diurnal maximum and minimum soil temperature among the depths. On an average the amplitude of soil temperature are about 2.0 " $\mathrm{C}$ and 1.0 " $\mathrm{C}$ at $35 \mathrm{~cm}$ depth in the case of observe and simulation, respectively. The exactly opposite peaks of soil temperature are observed between the values of surface and at $35 \mathrm{~cm}$ depth at noon time and before dawn. With carrying a smaller angular difference between the depth direction $\mathrm{Z}$ and vertical direction $\mathrm{Z}$ ' i.e. $20^{\circ}$ the observed results are therefore, showing almost the same trend with the results reported by Hanks and Ashcroft(1980) for the case of bare flat field. They also reported the opposite peaks of soil temperature between $1 \mathrm{~cm}$ and $32 \mathrm{~cm}$ depth at noon time and soil temperature amplitude of 1.5 " $\mathrm{C}$ at $32 \mathrm{~cm}$ depth.

\section{Soil moisture}

Only a slight difference is observed between soil moisture profile of south and north facing fields. Fig.5a and Fig.5b presents the observed and simulated volumetric soil moisture profile of south facing field, respectively, where Fig.6a and Fig.6b presents observed and simulated volumetric moisture content for the case of north facing field, respectively. It is clearly shown in the results that surface soil of south facing field has reached air dry value after 1 day of experiment, but 2 days are required in the case of north facing field. It is due to different amount of heat available at the soil surfaces of south and north facing field. As in the case of soil temperature, the time lag is present for obtaining diurnal driest and wettest conditions among the depths in the case of simulation. Being a smaller angular difference between the depth direction $\mathrm{Z}$ and vertical direction $Z^{\prime}$ as mentioned already the obtained results are almost identical with the results reported by Sui et $a l$. (1992) for the case of bare flat field. They also reported the same tendency of diurnal up and down in moisture content at $5 \mathrm{~cm}$ depth of soil. As a whole, a slightly drier soil profile is obtained in the south facing field than that of north facing field.

Furthermore, no moisture difference is found on surface direction in both simulation and observe cases. It might be due to a small rainfall (i.e. about $50 \mathrm{~mm}$ ) one day before starting experiment, which is not enough for ocurring gravity flow. As above mentioned fluctuation on moisture content are found in simulation cases both of north and south facing fields. But in the case of observation fluctuations in soil moisture content are not presented, because readings for observation were done once a day at 6:00 a.m.. Therefore, tendencies shown by observed values are little bit different than that of simulation case. 


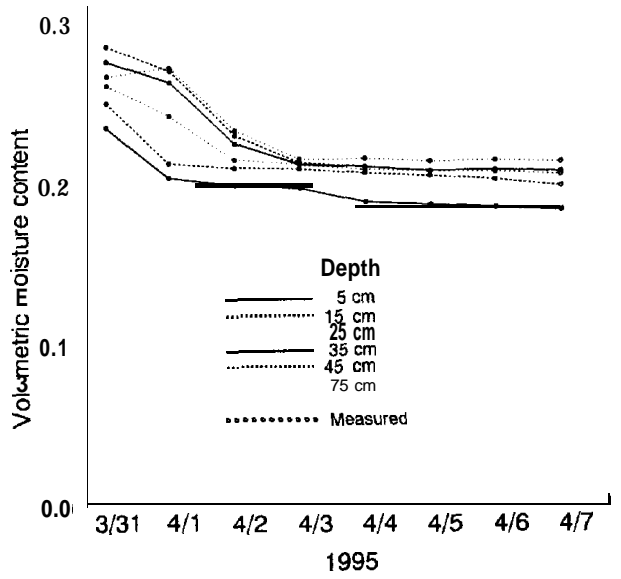

Fig. 5a. Observed volumetric soil moisture on south facing field.

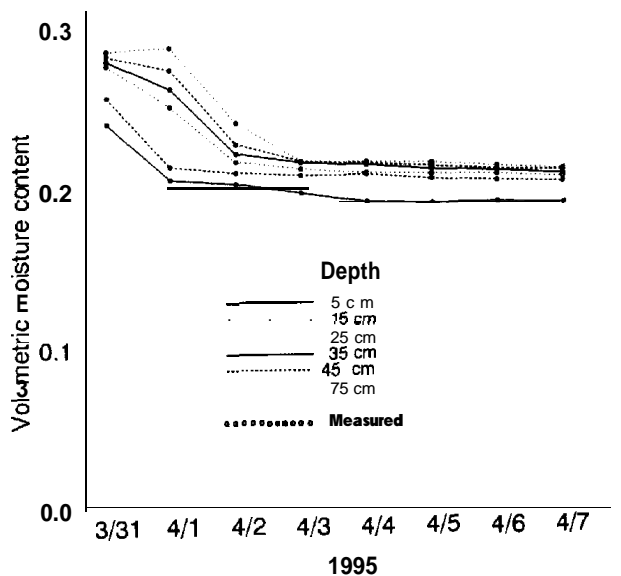

Fig. 6a. Observed volumetric soil moisture on north facing field.

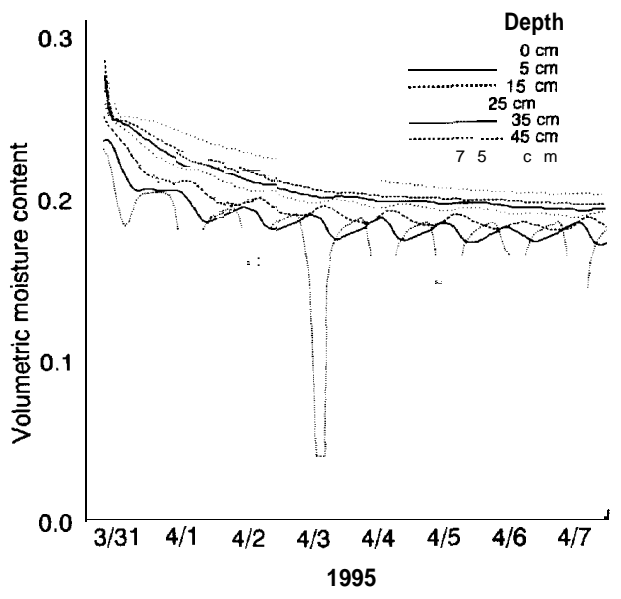

Fig. 5b. Simulated volumetric soil moisture on south facing field.

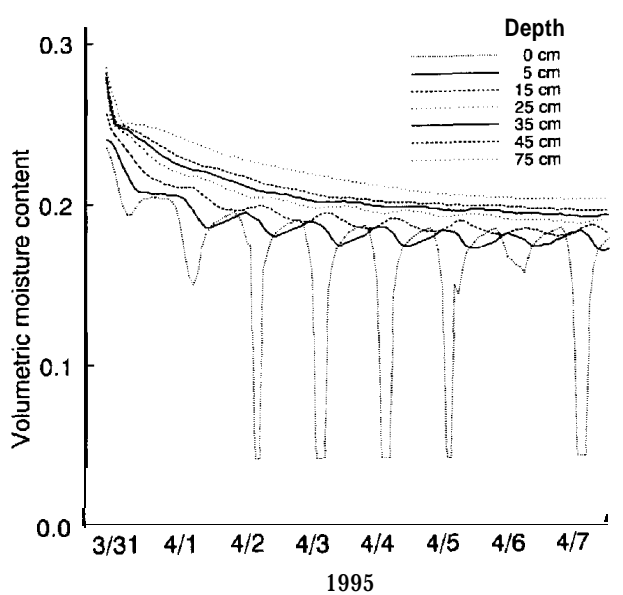

Fig. 6b. Simulated volumetric soil moisture on north facing field. 


\section{Surface energy fluxes}

The Fig.7 presents the diurnal value of different types of energy fluxes at the soil surface of south facing field. The results show that at noon time most of the net radiation energy is utilized by ground heat flux. In addition a considerable amount of net radiation energy is consumed in sensible heat flux and only a very small amount is utilized by evaporative heat flux. These conditions are led by a bit drier soil profile condition.

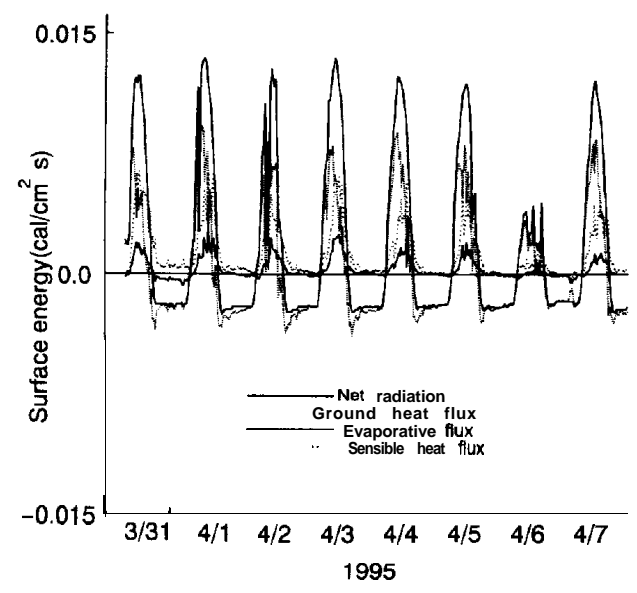

Fig. 7. Surface energy balance on south facing field.

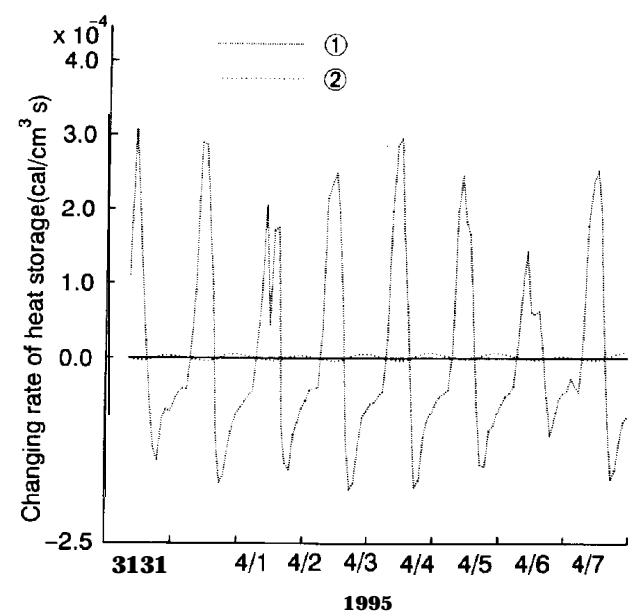

Fig. 8. Contribution of different types of gradient on changing rate of heat storage on south facing field at 5 and $45 \mathrm{~cm}$ depths.

Note: Contribution of four various types of gradient in eq. (8) were investigated but only one type of gradient i.e. second term of right hand side in eq. (8) has effeted changing rate of heat storage.

(1) Rate due to prod. of temp. grad. of depth dir. and thermal cond. at $5 \mathrm{~cm}$

(2) Rate due to prod. of temp. grad. of depth dir. and thermal cond. at $45 \mathrm{~cm}$ 


\section{Gradients inducing heat flow}

Contribution of various types of gradient on heat flow is investigated. This analysis is performed with considering the relation presented in eq.(8). The Fig. 8 presents the contribution of different types of gradient on changing rate of heat storage in south facing field at 5 and $45 \mathrm{~cm}$ depths. A significant difference is found between the results of these depths. In both depths changing rate of heat storage is only contributed by the product of temperature gradient of depth direction and thermal conductivity. The remaining other gradients have not contributed in changing rate of heat storage because of smaller angular difference between depth direction $\mathrm{Z}$ and vertical direction $\mathrm{Z}$ '. But the magnitude and amplitude of values of changing rate of heat storage are gradually decreasing with depth. At $5 \mathrm{~cm}$ depth the values are high whereas, the values are very nominal at $45 \mathrm{~cm}$ depth, which is clearly presented in Fig. 8.

\section{Gradients inducing moisture flow}

On the other hand, contribution of various types of gradient on moisture flow is investigated with the relation given by above mentioned eq. (7). The results of contribution of different types of gradient on changing rate of moisture content regarding the south facing field at 5 and $45 \mathrm{~cm}$ depths are presented in Fig. $9 \mathrm{a}$ and Fig. 9b, respectively. The results show that changing rate of moisture content is affected by 3 types of gradient the first, product of gravitational head gradient of depth direction and moisture conductivity, the second, product of moisture gradient of depth direction and moisture diffusivity and the third, product of temperature gradient of depth direction and thermal diffusivity. The remaining other gradients of surface direction have not shown any contribution on changing rate of moisture content as presented in Fig. 9.

The results show that contribution of the first type of gradient of above mentioned i.e. the product of gravitational head gradient of depth direction and moisture conductivity on changing rate of moisture content is becoming prominent as the depth increases due to the same reason of above mentioned i.e. smaller angular diffrence between depth direction $\mathrm{Z}$ and vertical direction $\mathrm{Z}$ '. But the contribution of this gradient is decreasing with time. On the other hand, the contribution of the second and the third types of gradient of above mentioned on changing rate of moisture content is decreasing with depth. Furthermore, a reciprocal relation is exist between the second and the third types of gradient. At $5 \mathrm{~cm}$ depth these gradients have possessed a considerable value, whereas values of these gradients are almost nil beneath $25 \mathrm{~cm}$ depth.

\section{CONCLUSIONS}

This research has came out with a brief conclusions as under mention.

1. The moisture content and temperature of soil profile is affected by the net accepted radiation by the field. Therefore, inclination and facing direction of field effect on the moisture content and temperature of soil profile as presented in Fig. 3 and Fig. 4.

2. Moisture flow along the surface direction were expected in the $20^{\prime \prime}$ inclined fields, but did not observed. It concluded that if moisture content in the soil profile is not enough to occur gravity flow or rainfall intensity is not higher than soil intake rate, then moisture 


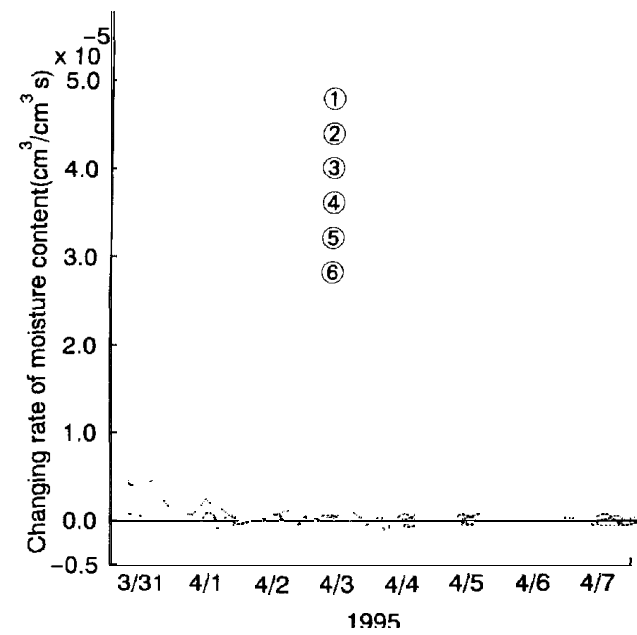

Fig. 9a. Contribution of different types of gradient on changing rate of moisture content in eq. (7) on south facing field at $5 \mathrm{~cm}$ depth.

Note:

(1) Rate due to prod. of temp. grad. of surf dir. and thermal dif.

(2) Rate due to prod. of temp. grad. of depth dir. and thermal dif.

(3) Rate due to prod. of moist. grad. of surf dir. and moist, dif.

(4) Rate due to prod. of surf. inclination grad and moist. cond.

(5) Rate due to prod. of moist. grad. of depth dir. and moist. dif.

(6) Rate due to prod. of grav. head grad. of depth dir. and moist. cond.

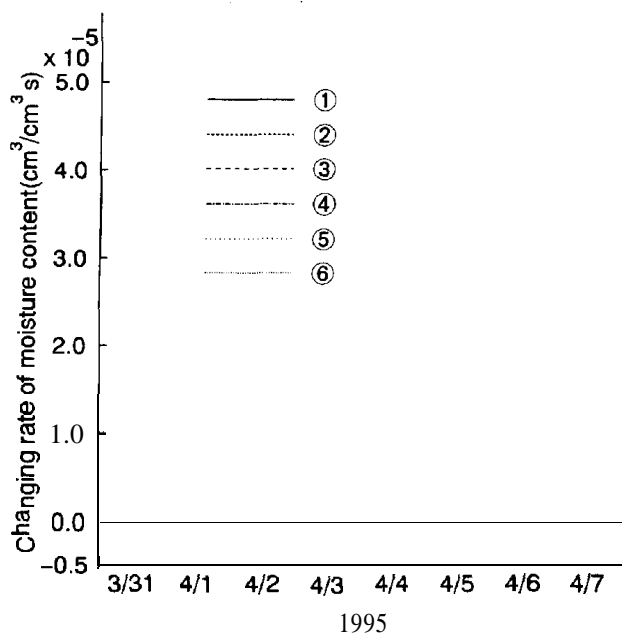

Fig. 9b. Contribution of different types of gradient on changing rate of moisture content in eq. (7) on south facing field at $45 \mathrm{~cm}$ depth.

Note:

(1) Rate due to prod. of temp. grad. of surf dir. and thermal dif.

(2) Rate due to prod. of temp. grad. of depth dir. and thermal dif.

(3) Rate due to prod. of moist. grad. of surf dir. and moist dif.

(4) Rate due to prod. of surf. inclination grad. and moist. cond.

(5) Rate due to prod. of moist. grad. of depth dir. and moist. dif.

(6) Rate due to prod. of grav. head grad. of depth dir. and moist. cond.

flow along the surface direction can not be found.

3. Changing rate of heat storage is solely contributed by the product of temperaturegradient of depth direction and thermal conductivity because depth direction $\mathrm{Z}$ has almost the same effect as vertical direction Z' has. Magnitude and amplitude of this gradient decreases as depth increases as shown in Fig.8. The other types of gradient have no any contribution on changing rate of heat storage in considered experimental field condition.

4. Changing rate of moisture content is significantly contributed by the product of gravitational head gradient of depth direction and moisture conductivity due to the same reason of above mentioned. i.e. depth direction $\mathrm{Z}$ has almost the same effect as vertical direction $Z$ ' has. The magnitude of contribution by this gradient increases with depth but decreases with time as shown in Fig. 9. On the other hand, contribution of the product of 
moisture gradient of depth direction and moisture diffusivity; and the product of temperature gradient of depth direction and thermal diffusivity on changing rate of moisture content have reciprocal relation. Magnitude of contribution of these gradients decreases with depth and becomes almost nil beneath $25 \mathrm{~cm}$ depth in sandy loam soil. The remaining other gradients of surface direction have no any contribution on changing rate of moisture content even in the $20^{\circ}$ inclined field with sandy loam soil.

5. The differences in soil moisture and temperature profiles are obtained mainly due to the different amount of net accepted radiation on the soil surface of north, south and flat fields not by the heat transport and moisture flow conditions inside the soil profile.

\section{REFERENCES}

Campbell, G. S. 1985 Soil Physics with Basic. Elsevier, New York, pp. 26-37

Chamberlain, A.C. 1968 Transport of gases to and from surfaces with bluff and wave-like roughnesselements. Quat. J. Roy. Met. Soc., 94: 318-332

de Vries, D. A. 1958 Simultaneous transfer of heat and moisture in porous media. Trans. Amer. Geophys. Union, 39(5): 909-916

Freeze, R. Allan 1971 Three-dimensional, transient, saturated-unsaturated flow in a ground water basin. Water Resources Res., 7(2): 347-366

Fritton, D. D., D. Kirkham and R. H. Shaw 1970 Soil water evaporation, isothermal diffusion, and heat and water transfer. Soil Sri. Soc. Amer. Proc., 34(2): 183-189

Goudriaan, J. 1977 Crop Micrometeorology a Simulation Study. Pudoc Wageningen, Centre for agricultural publishing and documentation, the Netherlands, pp. 73-93

Hanks, R. J. and G. L. Ashcroft 1980 Applied Soil Physics. Springer-Verlag, New York, pp. 125-143

Hillel, D. 1980 Fundamentals of Soil Physics. Academic Press, New York, pp. 287-313

Kjelgaard, J. F., C. 0. Stockle, J. M. Villar Mir, R. G. Evans and G. S. Campbell 1994 Evaluating methods to estimate corn evapotranspiration from short-time interval weather data. Trans. ASAE., 37(6):18251833

Lamsal, K., M. Kuroda and Y. Nakano 1995 Stochastic and three dimensional computation model for analyzing soil water balance on complex topography. J.Fac.Agr.,KyushuUniv,,39(3,4): 197-220

Miyazaki, T., S. Hasegawa and T. Kasubuchi 1993 Water Flow in Soils. Marcel Dekker Inc., New York, pp. $123-167$

Murai, K. 1978 Amount and intensity of solar radiation. In "Basic Theory and Application of Solar Energy", ed. by Soc. of Japan Solar Energy, Omusha, Tokyo, pp.1-34(in japanese)

Nakano, Y., T. Cho and D. Hillel 1983 Effect of transient, partial-area shading on evaporation from a bare soil. Soil Sci.,135(5): 282-295

Philip, J. R. and D. A. de Vries 1957 Moisture movement in porous materials under temperature gradients. Trans. Amer. Geophys. Union, 38(2): 222-232

Remson, I., George M. Hornberger and Fred J. Molz 1971 Numerical Methods in Subsurface Hydrology. John Wiley and Sons Inc., New York, pp. 164-177

Sui, H., D. Zeng and F. Chen 1992 A numerical model for simulating the temperature and moisture regimes of soil under various mulches. Agr. und For. Met., 61: 281-299

Tajima, T., H. Ono, Y. Sakata and M. Sugiura 1977 Computer Graphics. Korona Pub., Tokyo, pp. 27-45(in japanese)

van Bavel, C. H. M. and D. I. Hillel 1976 Calculating potential and actual evaporation from a bare soil surface by simulation of concurrent flow of water and heat. Agr. Met., 17: 453-476 